\title{
Physiological Difference between Dietary Obesity-Susceptible and Obesity-Resistant Sprague Dawley Rats in Response to Moderate High Fat Diet
}

\author{
InSurk J ANG1), DaeY eon HWANG2), J uE un LEE2), KabRyong CHAE 2), \\ YongK yu KIM2), TaeSeok KANG2), ChulKyu KIM2), DongH wan SHIN2), \\ J inHee $\mathrm{HWANG}^{2)}$, YoungBuhm $\mathrm{HUH}^{3)}$, and J ungSik $\mathrm{CHO}^{2)}$
}
1)Department of Animal Science \& Biotechnology, RAIRC, Jinju National University, 150 Chilam-Dong, Jinju, KyeongNam, ${ }^{2}$ Laboratory Animal Resources, National Institute of Toxicological Research, Korea FDA, Nokbun-Dong, Eungpyung-Ku 5, Seoul, and ${ }^{3)}$ Department of Anatomy, College of Medicine, Kyunghee University, Hoeki-Dong 1, Dongdaemum-Ku, Seoul, Korea

\begin{abstract}
The primary aim of the present study was to define central and peripheral physiological differences between dietary obesity-susceptible (DOS) and obesity-resistant $(D O R)$ outbred Sprague Dawley $(S D)$ rats when given a moderate high fat diet containing $32.34 \%$ of energy as a fat. After a 9-week feeding period, the DOS-SD rats consumed significantly more feed (11.1\%) and had higher abdominal (39.9\%) and epididymal (27.5\%) fat pads than the DOR-SD rats. In addition, serum leptin and insulin levels were significantly increased in the DOS-SD rats compared with those in the DOR-SD rats. However, we did not observe significant differences in serum triglyceride, cholesterol and glucose. No differences in hypothalamic OB-Ra and Rb mRNA expressions were found between the two groups. In contrast, arcuate NPY immunohistochemical expression was much higher in the DOS-SD rats than in the DOR-SD rats, though NPY expression in the supraoptic and paraventricular nuclei was not different between the two phenotypes. In peripheral tissues, the DOS-SD rats showed noticeably increased acetyl CoA carboxylase (ACC) mRNA expression in the liver, not epididymal fat. However, Western blot of peroxisomal proliferator activated factor $\gamma(P P A R \gamma)$ in the liver and epididymal fat was not different between the two phenotypes of $S D$ rats. It was concluded that different body weight phenotypes within outbred $S D$ population responded differently to the development of dietary induced obesity via altered anabolic features in the hypothalamus and liver.
\end{abstract}

Key words: DOR, DOS, hypothalamus, liver, physiological differences

(Received 11 March 2002 / Accepted 9 December 2002)

Address corresponding: I. Jang, Department of Animal Science and Biotechnology, RAIRC, Jinju National University, 150 Chilam-dong, Jinju, KyeongNam, 660-758, Korea 


\section{Introduction}

The etiology of human obesity appears to be mostly due to polygenic factors and response of dietary fat [27]. In particular, several studies suggested that dietary fat might be an important factor associated with the incidence of obesity in humans and rodents [10, 26]. The advantage of dietary obesity susceptible rats over the whole population of rats is that this model is much more prone to mechanisms underlying obesity that are applicable to humans in comparison with the other obesity prone rodents [16]. It was reported that one- half of Sprague Dawley (SD) rats appeared to develop obesity when rats were fed diets moderately high in energy and fat [18]. Almost all of the obesity studies with polygenic outbred strains have been conducted without consideration of the phenotype of obesity, such as obesity susceptibility or resistance. Moreover, a considerable heterogeneity exists even within the same strain in the development of obesity [19]. Thus, it is reasonable to examine adiposity and its related genes between dietary obesity resistant (DOR) and susceptible (DOS) SD rats within the population. Especially, serum leptin produced from adipose tissues is believed to act as a signal for body fat storage through the hypothalamic leptin receptor (OB-R) regulating food intake via neuropeptide Y (NPY) [29]. Besides the central mechanism of obesity control, peripheral adipogenic genes such as acetyl carboxylase CoA (ACC) and peroxisome proliferator activated receptor $\gamma$ $(\operatorname{PPAR} \gamma)$ may be considered as key lipogenic factors affecting body fat mass [8].

Therefore, the present study was designed to compare the effect of dietary high fat on weight gain, body fat mass, serum leptin, expressions of hypothalamic OB$\mathrm{R}$ and NPY and expressions of ACC and PPAR $\gamma$ between DOR and DOS-SD rats.

\section{Materials and Methods}

\section{Experimental animals, diet and procedures}

A total of thirty 6-week-old male Crj: CD (SD) originated from Charles River, Japan were maintained under a barrier system with regulated temperature $\left(23 \pm 2^{\circ} \mathrm{C}\right)$, humidity $(50 \pm 10 \%)$ and light: dark cycle (light on 07:00-19:00 h). All animal experiments were performed in compliance with KFDA guidelines for care
Table 1. Composition of purified diet containing moderate high fat

\begin{tabular}{lc}
\hline \multicolumn{1}{c}{ Components } & Purified diet \\
\hline Casein, \% & 20 \\
Corn oil, \% & 16 \\
Cellulose, \% & 5 \\
Starch, \% & 49 \\
Sucrose, \% & 5 \\
DL-Methionine, \% & 0.3 \\
Choline-Cl ${ }_{2}, \%$ & 0.2 \\
AIN-76 mineral mix, \% & 3.5 \\
AIN-76 vitamin mix, \% & 1.0 \\
-------------- \\
Energy, KJ/kg & ---630 \\
Fat, \% 1 & 32.34 \\
\hline
\end{tabular}

${ }^{1}$ Fat as $\%$ of total calories.

and use of laboratory animals. After feeding purified diet containing 5\% corn oil ad libitum for 3 weeks, we first divided thirty SD rats into two categories (higher weight gain; lower weight gain) on the basis of body weight gain. After that, the 10 heaviest rats in higher weight gain group were designated as dietary obesity susceptible (DOS) and the 10 lightest rats in lower weight gain group were selected as dietary obesity resistant (DOR) rats. The remaining 10 rats were not used for this study. The rats selected as DOS- and DOR-SD rats were housed singly in polycarbonated cages, respectively, according to order of body weight and continuously given ad libitum the purified diet containing moderate high fat $(16 \%$ corn oil) as an experimental diet (Table 1) for another 9 weeks to characterize physiological differences between the two phenotypes. Weekly body weights and daily food intakes were measured during the entire experimental period. At the end of the feeding period, corresponding rats were sacrificed in pairs by anesthesia with sodium pentobarbital $(100 \mathrm{mg} / \mathrm{kg})$ following $4-6 \mathrm{~h}$ deprivation of feed at a fixed time between 14:00-16:00. Blood was drawn by heart puncture and serum was isolated. The liver, hypothalamus and abdominal and epididymal fat were collected, weighed and rapidly frozen in liquid nitrogen. The tissues were then stored at $-70^{\circ} \mathrm{C}$ until further assay.

\section{Serum biochemical analyses}

Serum glucose, triglyceride and cholesterol were 
measured using a clinical biochemical analyzer (H1 system, Technicon, USA). Serum insulin and leptin were assayed by Linco RIA insulin and leptin kits (Linco Research, MO), respectively using $\gamma$-counter (COBRA $^{\text {TM }}$ II, Packard Bioscience, CT). All the analyses were conducted in duplicate.

\section{Semi-quantification of $O B-R$ and ACC $m R N A$}

Total RNA was isolated from the hypothalamus, liver and epididymal fat by the method of RNAsol B (TelTest, TX). Briefly, $100 \mathrm{mg}$ tissue was removed from each organ and added to $1 \mathrm{ml}$ of RNAsol solution. The samples were cut by scissor and homogenized using glass-glass homogenizer. The lysate was transferred to a microcentrifuge tube and added to $1 / 10$ volumes of chloroform to remove protein extract. The aqueous phase was separated by centrifugation for $15 \mathrm{~min}$ at $15,000 \mathrm{rpm}$. Total RNA was precipitated with the same volume of isopropanol and centrifuged for $15 \mathrm{~min}$ at $15,000 \mathrm{rpm}$. The precipitated total RNA was washed with $75 \%$ ethyl alcohol, then dried and diluted with DEPC treated water. The concentration of isolated total mRNA was determined by spectrophotometer and confirmed on a $1.0 \%$ agarose gel stained with ethidium bromide (EtBr).

Semi-quantification of mRNA using RT-PCR was performed to quantify mRNA of the leptin receptors such as the extracellular region common to all isoforms (OB-Ra; $814 \mathrm{bp}$ ), and the intracellular domain of the long form (OB-Rb; $511 \mathrm{bp}$ ) and acetyl CoA carboxylase (ACC; $580 \mathrm{bp}$ ). In brief, for synthesis of first strand cDNA, 5 $\mu \mathrm{g}$ of total RNA was incubated at $62^{\circ} \mathrm{C}$ for 10 min with $5 \mu \mathrm{g}$ of oligo dT. The resulting solution was continuously incubated at $42^{\circ} \mathrm{C}$ for $50 \mathrm{~min}$ in a reaction mixture containing $2.5 \mathrm{mM}$ dNTP and 200 units reverse transcriptase (Gibco BRL 18064-014, NY). After that, it was treated with 3.2 unit RNAase $\mathrm{H}$ to remove RNA produced by cDNA for $30 \mathrm{~min}$ at $37^{\circ} \mathrm{C}$. The amplification was performed by 30 cycles of denaturation at $94^{\circ} \mathrm{C}$ for $30 \mathrm{~s}$, annealing at $62^{\circ} \mathrm{C}$ for $30 \mathrm{~s}$ and extension at $72^{\circ} \mathrm{C}$ for 7 min with a PCR system. The reaction mixture contained 10 pmol primer, $0.5 \mu \mathrm{g}$ cDNA, $2 \mathrm{mM}$ dNTP and 1 unit Taq polymerase. The products were confirmed on a $1.0 \%$ agarose gel stained with EtBr. The cDNA primers to amplify each gene were as follows: 5'TGGGTGTCTATCTCTGAAGTAAG-3' and 5'-AATGGTGCTTTTGTTTGGCTG-3' for OB-Ra
(Gene bank accession no U52966), 5'TATGGAAGGAGTTGGAAAACC-3, and 5'-TAACTGAGGGTTGACTCTGAC-3' for OB-Rb (Gene bank accession no U52966) and 5'GACAGGTTCAAGCTGAAGTC-3, and 5'-TCCTGAACTGTTCCAGAGCT-3' for ACC (Gene bank accession no JO3808). The internal standard primers were 5'-GTGGGGCGCCCCAGGCACCAGGGC-3' and 5'-CTCCTTAATGTCACGCACGATTTC-3' for $\beta$ actin. We determined the number of cycles and kept the products within the exponential phase. The density of each product in Agarose gel electrophoresis (1\%) containing EtBr was quantified using a densitometer (Kodak EDAS 120, CT). Levels of all mRNAs were expressed as the ratio of signal intensity for genes relative to that for $\beta$-actin.

\section{Immunohistochemical assay of hypothalamic NPY}

Immunohistochemical assay was performed as previously described [15]. In brief, male SD rats $(n=2)$ were perfused with $4 \%$ freshly prepared paraformaldehyde in $0.1 \mathrm{M} \mathrm{PB}(\mathrm{pH} ; 7.4)$. The removed brains were postfixed in the same fixative overnight and continuously cryoprotected with $20 \%$ sucrose in $50 \mathrm{mM}$ PBS ( $\mathrm{pH}$; 7.4) for $48 \mathrm{~h}$. Frozen sections of $40 \mu \mathrm{m}$ thickness in the coronal plane were stained for immunohistochemical detection of NPY using rabbit polyclonal antiserum (Incstar Corp, MN). Next, free-floating sections were incubated for $72 \mathrm{~h}$ in PBS $\left(4^{\circ} \mathrm{C}\right)$ containing anti-NPY antiserum (1: 2,000 dilution), $0.3 \%$ Triton X$100,0.5 \mathrm{mg} / \mathrm{ml}$ bovine serum albumin and $1.5 \%$ normal goat serum. Sections were then incubated with goat anti-rabbit secondary antibodies (1: 100, Vector, CA) for $90 \mathrm{~min}$ and with avidin biotin-peroxidase complex (1: 100, Vector, CA) for $1 \mathrm{~h}$ at room temperature. Sections were reacted with $0.02 \% 3,3$ ' diaminobenzidine tetrahydrochloride and $0.01 \% \mathrm{H}_{2} \mathrm{O}_{2}$ for $3 \mathrm{~min}$.

\section{Western immunoblot assay of PPAR $\gamma$}

Briefly, protein extracts were prepared from the liver and epididymal fat by polytron homogenization in extraction buffer containing 4\% SDS and 10,000 x g centrifugation at $4^{\circ} \mathrm{C}$ for $30 \mathrm{~min}$. Protein concentration was assessed by a bicinchoninic acid kit (Pierce, IL). A $50 \mu \mathrm{g}$ protein was applied to $10 \%$ SDS-PAGE gel and the fractionated proteins were transferred to Hynond-P nitrocellulose membranes (Amersham, NJ). 
Membranes were first incubated with antibody against polyclonal PPAR $\gamma$ recognizing only the $\mathrm{N}$-terminal portion of PPAR $\gamma\left(1: 400\right.$, Santacruz, CA) for $1 \mathrm{~h}$ at $25^{\circ} \mathrm{C}$, then immediately washed three times and incubated with the secondary antibody, goat anti-mouse IgG horseradish peroxidase (1: 1,000, Amersham, IL). Protein band was visualized by ECL Western blotting system (Amersham, IL).

\section{Statistical analysis}

Student's $t$-test (paired) was used to compare the results between the DOR- and DOS-SD groups consumed moderate high fat diet. The level of probability for statistical difference was determined as $\mathrm{P}<0.05$.

\section{Results}

\section{Apparent Biological Parameters}

Body weight, weight gain and daily food intake during the feeding trial are presented in Fig. 1. The weekly and cumulative body weight for the 9-week feeding period increased in the DOS-SD rats compared with the DOR-SD rats (Fig. 1, A). The difference in body weight between the two phenotypes of rat was more apparent from 3 weeks after the start of the feeding trial. The rate of weight gain at 9 weeks was significantly $(\mathrm{P}<0.05)$ greater for DOS-SD than DOR-SD rats (Fig. 1, B).

The DOS-SD rats consumed $11.1 \%$ more average daily feed compared with the DOR-SD rats during the entire feeding period (Fig. 1, C). As a result of consuming the diet containing moderate high fat for 9 weeks, weights of abdominal and epididymal fat pads were significantly $(\mathrm{P}<0.05)$ greater in the DOS-SD rats than in the DOR-SD group (Fig. 2, A). The DOS-SD rats had $39.9 \%$ more $(\mathrm{P}<0.05)$ abdominal fat and $27.5 \%$ more $(\mathrm{P}<0.05)$ epididymal fat mass than the DOR-SD rats. When fat pads were calculated as per $100 \mathrm{~g}$ body weight, the statistical differences still remained between the two groups (Fig. 2, B). However, we did not observe marked differences in serum biochemical components including triglyceride, glucose and cholesterol between the two phenotypes (Fig. 3, A). There were statistical differences $(\mathrm{P}<0.05)$ in serum insulin and leptin levels between the DOR-SD and DOS-SD rats (Fig. 3, B). The DOS-SD rats showed a significant increase in both serum leptin and insulin levels when compared with the DOR-SD rats.
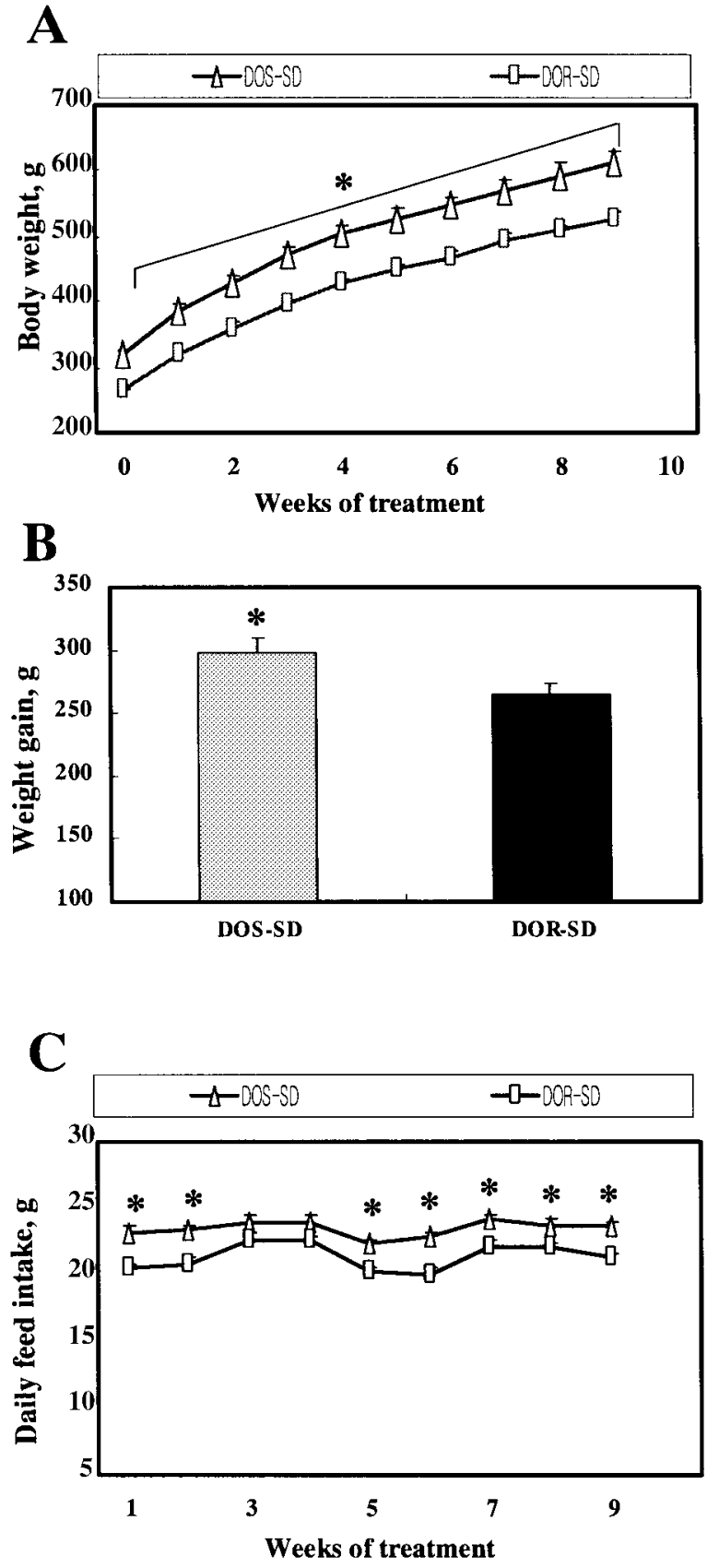

Fig. 1. Body weight (A), weight gain for 9 weeks (B) and daily feed intake $(C)$ in the DOS- and DOR-SD rats fed the purified diet containing moderate high fat. The values represent means \pm SE $(n=10)$. *Significantly different at $\mathrm{P}<0.05$ by paired $t$-test between the two phenotypes of SD rats. 

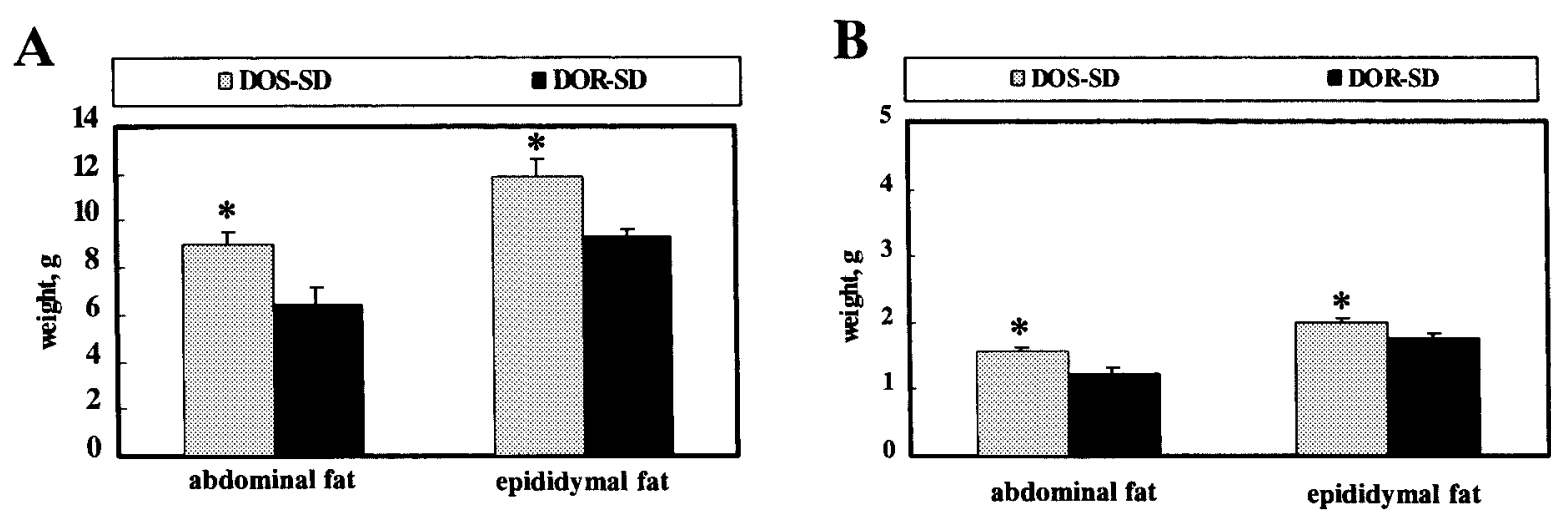

Fig. 2. Weights of total (A) and relative (g/100 g BW; B) abdominal and epididymal fat pads in the DOS- and DOR-SD rats fed the purified diet containing moderate high fat. The values represent means $\pm S E(n=5)$. *Significantly different at $\mathrm{P}<0.05$ by paired $t$-test between the two phenotypes of SD rats.
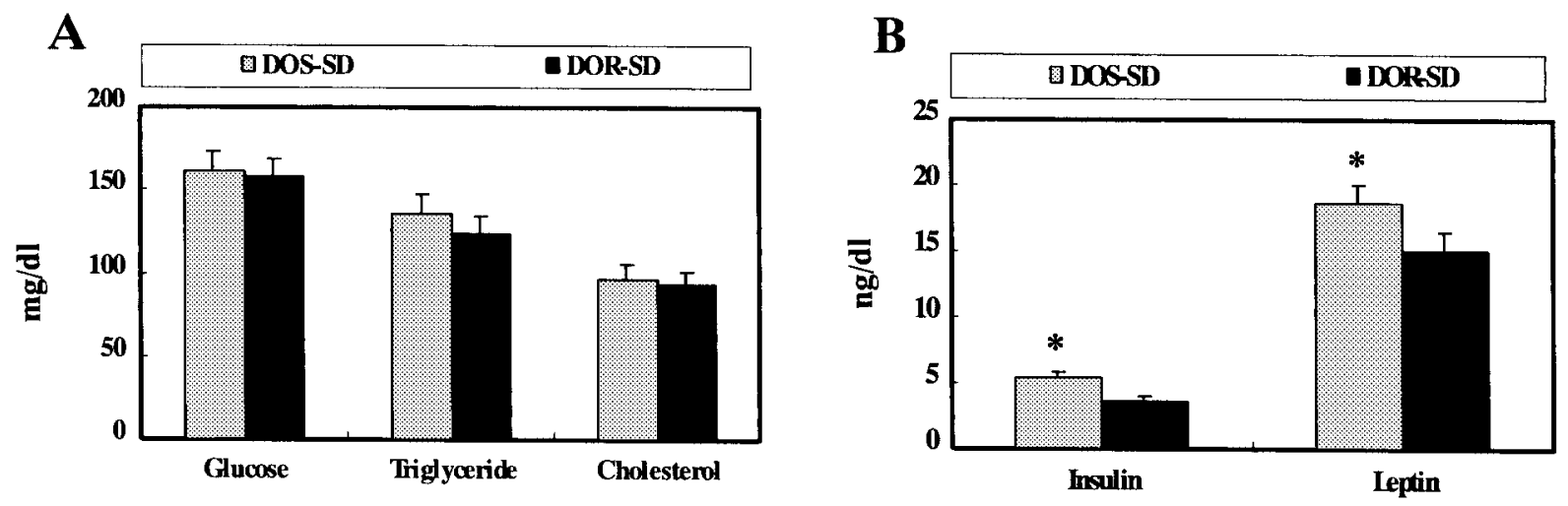

Fig. 3. Serum biochemical components (A) and hormone (B) levels in the DOS- and DOR-SD rats fed the purified diet containing moderate high fat. The values represent means $\pm \mathrm{SE}(\mathrm{n}=8)$. *Significantly different at $\mathrm{P}<0.05$ by paired $t$-test between the two phenotypes of SD rats.

\section{Expressions of $O B-R, N P Y, A C C$ and PPAR $\gamma$}

To examine possible alterations in the regulation of OB-R of the hypothalamus between the two phenotypes of rats in response to the moderate high fat diet, we examined mRNA expression of hypothalamic OB$\mathrm{R}$ by semi-quantification with RT-PCR (Fig. 4). Expressions of OB-R mRNAs including OB-Ra and $\mathrm{OB}-\mathrm{Rb}$ were not altered between the DOR and DOSSD rats. Thus, the phenotypes of SD rats by dietary fat did not significantly modulate hypothalamic leptin receptor transcripts. Also, we compared the immunohistochemical assay of NPY in the arcuate, paraventricular and supraoptic nuclei from the hypothalamus between the DOS and DOR-SD groups (Fig. 5). NPY immunohistochemical expression in the arcu- ate was much higher in the DOS-SD rats than in the DOR-SD rats. However, NPY expression in the paraventricular and supraoptic nuclei was not different between the two groups.

In order to examine the effects of moderate high fat on peripheral adipogenesis between the two groups, we measured ACC mRNA and PPAR $\gamma$ protein expressions in the liver and epididymal adipose tissues (Figs. 6 and 7). ACC is a key enzyme for the synthesis of fatty acids in the liver and adipose tissues and PPAR $\gamma$ appears to play a crucial role in adipocyte differentiation and the storage of lipids. Hepatic ACC mRNA expression was markedly lower in the DOR-SD than in DOS-SD rats, whereas epididymal ACC mRNA expression was not significantly different between the two 

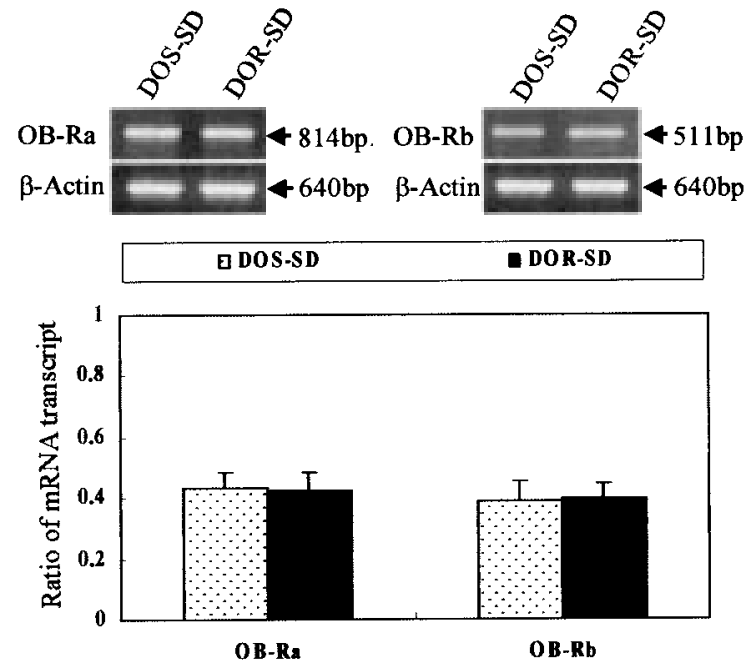

Fig. 4. The expression of OB-Ra and Rb mRNAs in the hypothalamus of the DOS- and DOR-SD rats $(n=5)$ fed the purified diet containing moderate high fat. The values represent means $\pm \operatorname{SE}(n=5)$.

groups (Fig. 6). However, we did not observe a significant change in PPAR $\gamma$ Western blot expression in the liver and epidydimal fat of either the DOS-SD or DOR-SD rats (Fig. 7).

\section{Discussion}

Most dietary induced obesity studies with outbred SD rats have shown a wide variability in metabolic and physiological phenomena according to genetic and dietary background $[17,19]$. Therefore, verification of how environmental factors with genetic background affect body adiposity between two phenotypes of SD rats was needed. Therefore, we selected DOS- and DOR$\mathrm{SD}$ rats to compare obesity-related central and peripheral physiological differences when the two phenotypes of the rats were given a moderate high fat diet. The DOS-SD rats showed a greater feed consumption and larger abdominal and epididymal fat pads and subsequently increased body weight.

The mechanisms by which the DOS-SD rats store body fat more efficiently than the DOR-SD rats in response to dietary fat have not been clearly elucidated, although several studies have been taken to identify metabolic factors between the two phenotypes. Here, we tried to determine whether different phenotypes of SD rat would affect leptin and leptin's signaling path- way. First, we examined leptin, known as a signal for the regulation of food intake through hypothalamic OB$\mathrm{R}$ to regulate body fat mass. We demonstrated that the circulating leptin level was positively correlated with adiposity and body weight in SD rats, which is in agreement with other studies using humans and rodents $[4$, $9,12]$, although other factors such as energy balance are also likely to influence leptin production in the adipocytes [14]. Surwett et al. (1995) [23] indicated that obesity prone mice elevated plasma leptin very gradually along with significant body fat mass in response to a high fat diet. It was observed that the DOS-SD rats increased both serum leptin level and body fat mass in our study.

As regards hypothalamic OB-R, however, we did not observe changes in OB-Ra and $\mathrm{Rb}$ mRNA expression from the two phenotypes of SD rats in response to high dietary fat. It was suggested that high dietary fat was likely not enough to provoke up-regulation of OB-R expression in dietary induced obesity animals [22]. Inconsistent with those observations, Lin et al. (2000) [21] indicated that dietary high fat in C57/BL mice resulted in a significant increase in OB-R mRNA in the hypothalamus. In addition, Zucker obese $(f a / f a)$ rats were associated with decreased leptin transport across the blood-brain barrier in the development of obesity [3]. The possible underlying mechanisms regarding the regulation of hypothalamic OB-R expression according to dietary fat largely remain to be elucidated.

NPY, a potent stimulator of feed intake, is mainly synthesized in the arcuate nucleus and injected into the paraventricular nucleus induced hyperphagia and reduced energy expenditure [28]. Therefore, we attempted to investigate the NPY expression differences in the arcuate, paraventricular and supraoptic regions of the hypothalamus between the two phenotypes. In our data, a significant increase in NPY expression in the arcuate nucleus of the DOS-SD rats may explain increased feed intake compared with that of the DOR-SD rats. Similar to the results of our study, a work with dietary induced obesity SD rats showed that these rats had $41 \%$ higher ARC NPY mRNA than their counterparts [20]. Resistance to high fat diet-induced obesity in C57BL/ $6 \mathrm{~J}$ was positively associated with decreased hypothalamic NPY mRNA [2]. It was documented that increased arcuate and paraventriculer nuclei NPY were observed in the genetically obese Zucker obese $(f a / f a)$ 


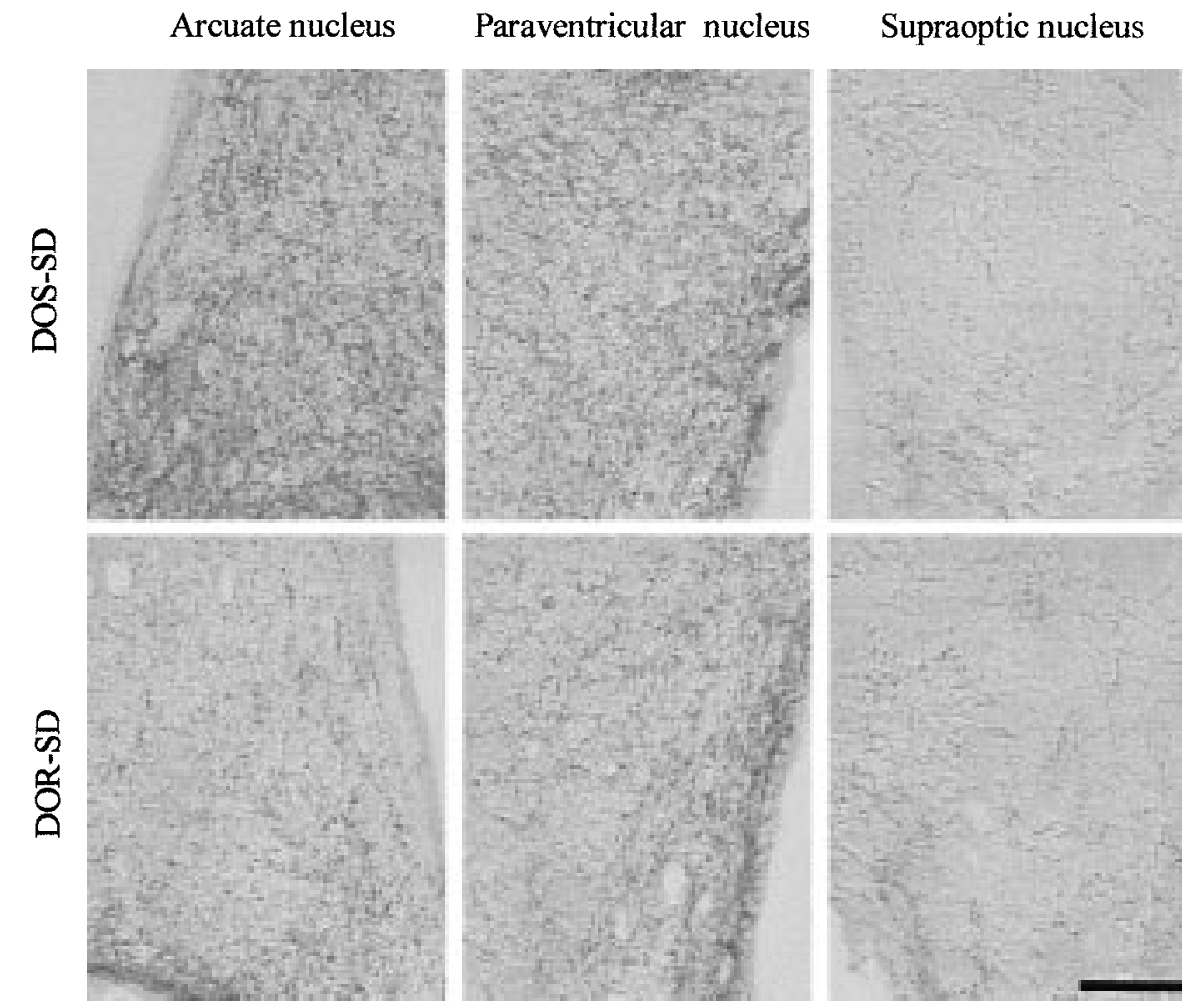

Fig. 5. NPY immunohistochemical assay in the hypothalamus (arcuate, paraventricular and supraoptic nuclei) of the DOS- and DOR-SD rats fed the purified diet containing moderate high fat $($ Scale bar $=216 \mu \mathrm{m})$.
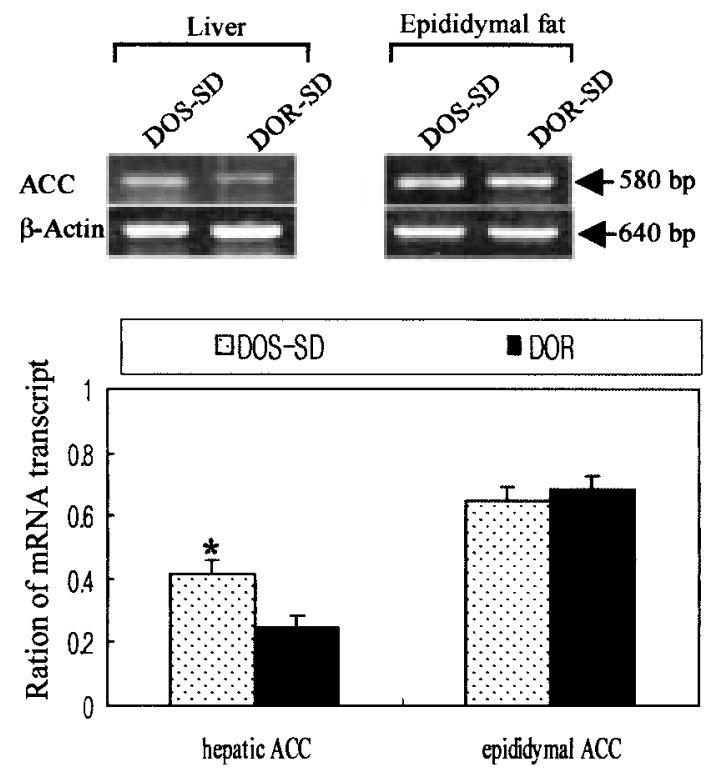

Fig. 6. The expression of ACC mRNAs in the liver and epididymal fat of the DOS- and DOR-SD rats fed the purified diet containing moderate high fat. The values represent means $\pm \mathrm{SE}(\mathrm{n}=5)$. *Significantly different at $\mathrm{P}<0.05$ by paired $\mathrm{t}-$ test between the two phenotypes of SD rats.

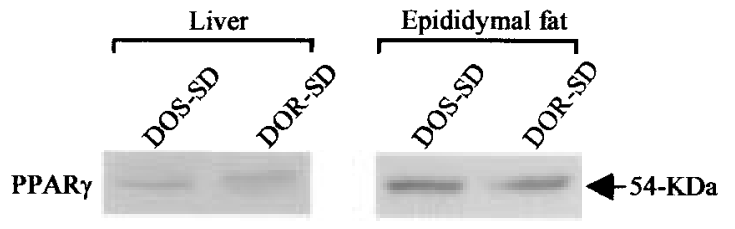

Fig. 7. Western blot of PPAR $\gamma$ in the liver and epididymal fat of the DOS- and DOR-SD rats fed the purified diet containing moderate high fat.

rats [1]. Several studies suggested that up-regulated hypothalamic NPY could be involved in increased feed intake and low energy expenditure and subsequently contribute to the development of dietary induced obesity [5].

As peripheral adipogenic genes are also known to be important regulators in obese animals, we thought that increased fat mass in the DOS-SD rats might be partially due to enhanced de novo lipogenesis in the liver and adipocytes. We demonstrated differential expression of ACC mRNA in the liver between DOS- and 
DOR-SD rats. It has been well demonstrated that obese animals exhibit a higher ACC expression, a key lipogenic enzyme, compared with lean animals $[6,7]$. Such a reduced hepatic ACC mRNA expression in the DORSD rats could result in down-regulation of de novo lipogenesis in response to moderate high fat. The $\operatorname{PPAR} \gamma$, especially PPAR $\gamma 2$, have been well demonstrated to be induced by high fat, leading to an increase in lipogenic gene expression in the liver and adipose tissues $[11,25]$. In particular, early overexpression of $\operatorname{PPAR} \gamma$ was responsible for induction of lipid storage and adipocyte specific genes, indicating that this transcriptional factor plays a crucial role in up-regulation of adipocyte differentiation. It was reported that expression of PPAR $\gamma$ was higher in the adipocytes of obese Zucker rats compared with lean rats [13]. Contradictory to genetically obese animals, epididymal and hepatic PPAR $\gamma$ expression did not differ between the DOR-SD rats and DOS-SD rats of our study. Therefore, it is likely that the phenotype difference in SD rats does not affect early adipogenic differentiation factors in the liver and adipocytes. In the present study, it is likely that the DOS-SD rats increased fat pad weight via increased hepatic ACC rather than adipocyte adipogenic factor. However, a more detailed study is needed to explore the morphological differences of adipose cells between the two phenotypes of SD rat.

In addition, susceptibility to dietary obesity in the DOS animals was partially due to a more positive fat balance resulting from burning less fat in response to the high fat diet [5]. These results are also in agreement with several studies, which demonstrated that DOS rats had greater energy efficiency, a lower rate of $\beta$ oxidation and fatty acid synthesis than the DOR rats [24]. However, the metabolic features of the diet-induced obese rats are relatively modest compared with genetically obese animals.

Overall, it is concluded from our study that up-regulated anabolic features including enhanced hypothalamic NPY and hepatic ACC may also be responsible for increased fat deposition in the DOS-SD rats compared with the DOR-SD rats. A wider physiological study regarding how the two phenotypes of SD rats regulate their body weight including lipolysis and adipocyte morphology is needed to understand dietary induced obesity in SD rats.

\section{References}

1. Beck, B., Burlet, A., Bazin, R., Nicolas, J.P., and Burlet, C. 1993. Elevated neuropeptide $\mathrm{Y}$ in the arcuate nucleus of young obese Zucker rats may contribute to the development of their overeating. J. Nutr. 123: 1168-1172.

2. Bergen, H.T., Mizuno, T., Taylor, J., and Mobbs, C.V. 1999. Resistance to diet-induced obesity is associated with increased proopiomelanocortin mRNA and decreased neuropeptide Y mRNA in the hypothalamus. Brain Res. 851: 198-203.

3. Burguera, B., Couce, M.E., Curran, G.L., Jensen, M.D., Lloyd, R.V., Cleary, M.P., and Poduslo, J.F. 2000. Obesity is associated with a decreased leptin transport across the blood-brain barrier in rats. Diabetes 49: 1219-1223.

4. Caro, J.F., Sinha, M.K., Kolaczynski, J.W., Zhang, P.L., and Considine, R.V. 1996. Leptin: the tale of an obesity gene. Diabetes 45: 1455-1462.

5. Chang, S., Graham, B., Yakubu, F., Lin D., Peters, J.C., and Hill, J.O. 1990. Metabolic differences between obesityprone and obesity-resistant rats. Am. J. Physiol. 259: 1103-1110.

6. Cheesma, S.K. and Clandinin, M.T. 1996. Diet fat alters expression of genes for enzymes of lipogenesis in lean and obese mice. Biochim. Biophys. Acta 1299: 284-288.

7. Clandinin, M.T., Cheesma, S.K., Pehowich, D., and Field, C.J. 1996. Effects of polyunsaturated fatty acids in obese mice. Lipids 31: 13-22.

8. Clarke, S.D. and Jump, D.B. 1994. Dietary polyunsaturated fatty acid regulation of gene transcription. Annu. Rev. Nutr. 14: 83-98.

9. Considine, R.V., Sinha, M.K., Heiman, M.L., Kriauciunas, A., Stephens, T.W., Nyce, M.R., Ohannesian, J.P., Marco, C.C., McKee, L.J., Bauer, T.L., and Caro J.F. 1995. Serum immunoreactive-leptin concentrations in normal-weight and obese humans. N. Eng. J. Med. 334: 292-295.

10. Dreon, D.M., Frey-Hewitt, B., Ellsworth, N., Williams, P.T., Terry, R.B., and Wood, P.D. 1988. Dietary fat: carbohydrate ratio and obesity in middle-aged men. Am. J. Clin. Nutr. 47: 995-1000.

11. Everett, L., Galli, A., and Crabb, D. 2000. The role of hepatic peroxisome proliferator-activated receptors (PPARs) in health and disease. Liver 20: 191-199.

12. Frederich, R.C., Hamann, A., Anderson, B., Lollmann, B., Lowell, B.B., and Flier, J.S. 1995. Leptin levels reflect body lipid content in mice: evidence for diet-induced resistance to leptin action. Nature Med. 1: 1311-1314.

13. Gorla-Bajszczak, A., Siegrist-Kaiser, C., Boss, O., Burger, A.G., and Meiser, C.A. 2000. Expression of peroxisome proliferator-activated receptors in lean and obese Zucker rats. Eur. J. Endocrinol. 142: 71-78.

14. Havel, P.J. 1998. Leptin production and action: Relevance to energy balance in humans. Am. J. Clin. Nutr. 67: 355356.

15. Huh, Y., Kim, C., Lee, W., Kim, J., and Ahn, H. 1997. Age-related changes in the neuropeptide Y and NADPHdiaphorase-positive neurons in the cerebral cortex and 
striatum of aged rats. Neurosci. Letters 223: 157-160.

16. Lauterio, T.J., Bond, J.P., and Ulman, E.A. 1994. Development and characterization of a purified diet to identify obesity-susceptible and resistant rat populations. J. Nutr. 124: 2172-2178.

17. Levin, B.E., Triscari, J., and Sullivan, A.C. 1983. Relationship between sympathetic activity and diet-induced obesity in two rat strains. Am. J. Physiol. 245: 367-371.

18. Levin, B.E., Finnegan, M., Triscari, J., and Sullivan, A.C. 1985. Brown adipose and metabolic features of chronic diet-induced obesity. Am. J. Physiol. 248: 717-723.

19. Levin, B.E. and Sullivan, A.C. 1987. Glucose-induced norepinephrine levels and obesity resistance. Am. J. Physiol. 253: 475-481.

20. Levin, B.E. and Dunn-Meynell, A.M. 1997. Dysregulation of arcuate nucleus preproneucropeptide Y mRNA in dietinduced obese rats. Am. J. Physiol. 272: 1365-1370.

21. Lin, S., Storlien, L.H., and Huang, X. Leptin receptor, NPY, POMC mRNA expression in the diet-induced obese mouse brain. Brain Res. 2000; 875: 89-95.

22. Peiser, C., McGregor, G.P., and Lang, R.E. 2000. Leptin receptor expression and suppressor of cytokin signaling transcript levels in high-fat-fed rats. Life Sci. 67: 29712981.
23. Surwit, R.S., Feinglos, M.N., Rodin, J., Sutherland, A., Petro, A.E., Opara, E. C., Kuhn, C.M., and Rebuffe-Scrive, M. 1995. Differential effects of fat and sucrose on the development of obesity and diabetes in C57BL/6J and A/J mice. Metabolism 44: 645-651.

24. Triscari, J., Nauss-Karol, C., Levin B.E., and Sullivan, A.C. 1985. Changes in lipid metabolism in diet-induced obesity. Metaboilsm 34: 580-587.

25. Tugwood, J.D., Aldridge, T.C., Lambe, K.G., MacDonald, N., and Woodyatt, N.J. 1996. Peroxisome proliferatoractivated receptors; structures and function. Ann. NY Acad. Sci. 804: 252-265.

26. West, D.B., Boozer C.N., Moody, D.L., and Atkinson, R.L. 1992. Dietary obesity in nine inbred mouse strains. Am. J. Physiol. 262: 1025-1032.

27. West, D.B. and York, B. 1998. Dietary fat, genetic predisposition, and obesity: lessons from animal models. Am. J. Clin. Nutr. 67: 505-512.

28. White, B.D. and Martin R.J. 1997. Evidence for a central mechanism of obesity in the Zucker rats: Role of neuropeptide Y and leptin. P.S.E.B.M. 214: 222-228.

29. Wolf, G. 1997. Neuropeptides responding leptin. Nutr. Rev. 55: $85-88$. 